\title{
EFFECTS OF GAME LOCATION, QUALITY OF OPPOSITION, NUMBER OF FOREIGN PLAYERS AND ANTHROPOMETRIC CHARACTERITICS IN ELITE HANDBALL GAMES
}

\author{
Thierry Debanne ${ }^{1}$ and Guillaume Laffaye $\mathrm{e}^{2,3}$ \\ ${ }^{1}$ Université Paris-Est, LIRTES (EA 7313), UPEC, UPEMLV, Créteil, France \\ ${ }^{2}$ CIAMS, Université Paris-Sud, Université Paris-Saclay, Orsay, France \\ ${ }^{3}$ CIAMS, Université d'Orléans, Orléans, France
}

Original scientific paper

UDC: 796.322:796.02:796.08

\begin{abstract}
:
The aims of this study were (1) to investigate the influence of game location, quality of opposition, age of players, and anthropometric characteristics of backcourt and pivot players as well as the number of foreign players in a team on goal difference between the teams in the French (LNH) and German (Bundesliga) national men's professional leagues, and (2) to predict goal difference of match final scores in these two national leagues using a multiple regression model. Archival data were obtained from the open access official websites to collect a sample of 165 handball matches ( $\mathrm{LNH}$ [N=89], and Bundesliga [N=76]) of the first part of the 2015/2016 regular season. The linear regression model predicted the winner in $79 \%$ of cases with a mean accuracy of four goals. The coefficients of determination found in both multiple regression models were $r^{2}=.67$ and $r^{2}=.49$ for the LNH and the Bundesliga, respectively. The models revealed a high contribution of the difference in the end-of-previous season goal-average per match ranking and a moderate contribution of the game location to goal difference. The models also highlighted differences in the way games were won in these leagues with a contribution of foreigners, anthropometric characteristics and age only in the Bundesliga.
\end{abstract}

Key words: multiple regression model, team sports, performance analysis

\section{Introduction}

Sports performance analysis can be used to investigate team performance and the determinants of success in a variety of team sports (O'Donoghue, 2015) that are characterized by the relationship of opposition between two teams having antagonist interests (Gréhaigne \& Godbout, 1995). Many studies have highlighted links between numerous variables and team performance. In team handball, available research highlighted the home court advantage effect (e.g., Gómez, Lago-Peñas, Viaño, \& González-Garcia, 2014; Lago-Peñas, Gómez, Viaño, \& González-Garcia, 2013; Pollard \& Gomez, 2012), and showed that team quality, as extracted from the final ranking in the competition, impacted game trends (Gómez, et al., 2014). Anthropometric and physical fitness characteristics also appear to be related to skill level and are directly related to the ability to throw the ball at high velocity (Debanne \& Laffaye, 2011; Laffaye, Debanne, \& Choukou, 2012), suggesting that these characteristics could affect a match's final result. For example, being taller offers physical advantage during the offensive game phase for high jumping and avoiding the defenders' wall. In addition, many studies have found clear and substantial differences in the body dimensions of players on different positions (e.g., Karcher, Ahmaidi, \& Buchheit, 2014; Karcher \& Buchheit, 2014) highlighting that wing players are smaller and lighter than pivot players and/or backcourt players. In other ways, from a team composition perspective, the recruitment of foreign players also seems to influence team performance (Meletakos, Chatzicharistos, Apostolidis, Manasis, \& Bayios, 2016), first by changing the team dynamics, and by allowing the productive use of member talents and resources (e.g., Earley \& Mosakowski, 2000; Elron, 1997). Last, age can influence team performance in that it is directly and positively linked to professional experience (Ali \& Davies, 2003), which could have a positive impact on team performance (Campbell, 1990; Hunter, 1983; Schmidt, Hunter, \& Outerbridge, 1986).

Although several studies have investigated the effect of these variables on team performance, little is known about the effect of the combination of 
these variables on handball results, either on the final win or loss result or on the goal difference. Therefore, based on the review of literature, the aims of this study were (1) to investigate the influence of game location (home or away), quality of the opposition (the previous-season ranking difference between the opposing teams), age of players, anthropometric characteristics of backcourt and pivot players, and the compositional diversity within the team (difference in the number of foreigners between the opposing teams) on the goal difference between the teams of the French (LNH) and German (Bundesliga) national men's major professional leagues; and (2) to predict goal difference of final scores of the matches in these two national leagues using a multiple regression model.

\section{Method}

\section{Data collection}

The study was approved by the university's ethics committee. Archival data were obtained from the open-access official websites of the French and German professional handball leagues (http:// www.lnh.frwww.lnh.fr; http:// www.dkb-handballbundesliga.de). A sample of 165 ( $\mathrm{LNH}$ [N=89], and DKB Bundesliga [N=76]) handball matches (a total 330 teams' individual game performances) were taken from the first part of the 2015/16 regular season.

\section{Data analysis}

Linear regression models were used to explore the effects of predictor variables on the goal difference for the French and German national leagues and for all matches. Eight independent variables were divided into two groups: (1) insofar as team sports are characterized by a relationship of opposition between two teams with antagonist interests and, as mentioned above, backcourt and pivot players need to be taller and heavier than wing players (e.g., Karcher, et al., 2014; Karcher \& Buchheit, 2014), the first group of variables included four differences in players' characteristics between the teams for each match: (a) the difference in mean body mass of backcourt and pivot players $\left(\Delta_{\mathrm{BM}}\right)$, (b) the difference in mean height of backcourt and pivot players $\left(\Delta_{\mathrm{H}}\right)$, (c) the difference in mean age of backcourt and pivot players $\left(\Delta_{\text {Age }}\right)$, and (d) the difference in the number of foreigners $\left(\Delta_{\mathrm{F}}\right)$; (2) the second group of variables included four situational variables: (a) game location (home $=1$, or away $=0$ ), noted (L), and (b) the quality of opposition identified from $\left(b_{1}\right)$ the difference in the ordinal ranking at the end of the previous season $\left(\Delta_{\mathrm{OR}}\right),\left(\mathrm{b}_{2}\right)$ the difference in the points ranking at the end of the previous season $\left(\Delta_{\mathrm{PR}}\right),\left(b_{3}\right)$ the difference in the goal-average per match ranking at the end of the previous season $\left(\Delta_{\mathrm{GA}}\right)$.
The analyses were performed using Statistica software (Version 10, Statsoft, Inc.). First, Pearson correlation coefficients were calculated to determine the relationship between independent variables in the two national leagues and all matches. We used the ranges described by Hopkins and colleagues for correlation effects, with threshold values of small, moderate, large, very large and nearly perfect correlations at $0.1,0.3,0.5,0.7$ and 0.9 , respectively (Hopkins, Marshall, Batterham, \& Hanin, 2009). Then, a multiple-regression analysis was used to identify the best predictive models. The basic model used the general linear model:

$$
\mathrm{Y}=\beta_{0}+\beta_{1} \cdot \mathrm{x}_{1}+\beta_{2} \cdot \mathrm{x}_{2}+\beta_{3} \cdot \mathrm{x}_{3}+\beta_{\mathrm{i}} \cdot \mathrm{x}_{\mathrm{i}}
$$

where $\mathrm{Y}$, the dependent variable representing the goal difference, is normally distributed, $x_{i}$ is the $i^{\text {th }}$ predictor, and $\beta_{\mathrm{i}}$ is the coefficient. Descriptive statistics were used to verify that the basic dependent variable assumption of normality was met. Distribution normality tests and skewness revealed no abnormal pattern in the data. To validate the applicability of the multiple regression equation, we used the same protocol to test an independent sample of 27 games (11 in the Bundesliga and 16 in the $\mathrm{LNH}$ ) using Howell's (2010) method. We used a paired $t$-test for each variable in the equation (comparison between the observed and the theoretical value of the coefficients in the equation). The criterion for statistical significance was set at $p<.05$ and the effect size was calculated for regression with Cohen's $f^{2}$ and for $t$-test with Cohen's $d$, that was defined as large (>.80), moderate (>.50) and small (>.20) (Cohen, 1988).

\section{Results}

\section{Differences in the Bundesliga and LNH leagues}

There are some significant differences between the German (Bundesliga) and French (LNH) leagues, such the height, body mass and age of backcourt and pivot players who were taller, heavier and older in the Bundesliga than in the LNH. Moreover, the mean difference in the number of foreigners per team was greater in the Bundesliga (3.05 \pm 2.22 ) than in the LNH $(2.09 \pm 1.57)$. These differences and the effect size are summarized in Table 1.

\section{Single regressions}

The correlations between the independent variables and goal difference are summarized in Table 2. All the independent variables were linked with goal difference in the Bundesliga, LNH and in all matches, excepted for the mean difference of foreigners per team in the LNH $(\mathrm{r}=.12, \mathrm{p}>.05$, $f^{2}=0.13$ ). 
Table 1. Comparison of the parameters studied between the Bundesliga and LNH using an independent Student t-test (ddl=328) and Cohen's d effect size

\begin{tabular}{lcccccc}
\hline Variables & Mean Bundesliga (SD) & Mean LNH (SD) & $\Delta \%$ & $t$ & $p$ & $d$ \\
\hline Foreigners per team & $5.63(2.62)$ & $5.22(1.72)$ & 7.85 & 1.69 & $\mathrm{~ns}$ & 0.18 \\
$\Delta_{\mathrm{F}}$ & $3.05(2.22)$ & $2.09(1.57)$ & 45.93 & 3.25 & .001 & 0.35 \\
Height $(\mathrm{m})$ & $1.945(0.02)$ & $1.931(0.02)$ & 7.25 & 6.25 & $<.001$ & 0.69 \\
$\Delta_{H}(\mathrm{~m})$ & $0.022(0.02)$ & $0.023(0.02)$ & -4.3 & -0.76 & $\mathrm{~ns}$ & 0.08 \\
Body mass $(\mathrm{kg})$ & $97.9(3.26)$ & $95.9(3.11)$ & 2.09 & 5.76 & $<.001$ & 0.60 \\
$\Delta_{\mathrm{BM}}(\mathrm{kg})$ & $4.00(4.94)$ & $3.60(4.44)$ & 11.11 & 0.94 & $\mathrm{~ns}$ & 0.10 \\
Age & $28.8(1.53)$ & $27.5(1.59)$ & 1.05 & 7.26 & $<.001$ & 0.87 \\
$\Delta_{\text {Age }}$ & $1.66(1.17)$ & $1.88(1.43)$ & -11.71 & -1.06 & $\mathrm{~ns}$ & 0.11 \\
Goal difference & $5.18(3.8)$ & $4.28(3.6)$ & 21.02 & 1.59 & $\mathrm{~ns}$ & 0.17 \\
\hline
\end{tabular}

Note. $\Delta_{\mathrm{F}}=$ difference in the number of foreigners; $\Delta_{\mathrm{H}}=$ difference in the mean height of backcourt and pivot players; $\Delta_{\mathrm{BM}}=$ difference in the mean body mass of backcourt and pivot players; $\Delta_{\mathrm{Age}}=$ difference in the mean age of backcourt and pivot players.

Table 2. Pearson correlations between goal score difference and independent variables

\begin{tabular}{lcccccc}
\hline \multirow{2}{*}{ Independent variables } & \multicolumn{2}{c}{ Bundesliga } & \multicolumn{2}{c}{ LNH } & \multicolumn{2}{c}{$\begin{array}{c}\text { All } \\
\text { (Bundesliga + LNH) }\end{array}$} \\
\hline & $r$ & $p$ & $r$ & $p$ & $r$ & $p$ \\
\hline & .35 & $<.001$ & .21 & .006 & .28 & $<.001$ \\
$\Delta_{\mathrm{OR}}$ & -.66 & $<.001$ & -.60 & $<.001$ & -.62 & $<.001$ \\
$\Delta_{\mathrm{PR}}$ & .68 & $<.001$ & .63 & $<.001$ & .65 & $<.001$ \\
$\Delta_{\mathrm{GA}}$ & .70 & $<.001$ & .68 & $<.001$ & .69 & $<.001$ \\
$\Delta_{\mathrm{F}}$ & .70 & $<.001$ & .12 & $n s$ & .44 & $<.001$ \\
$\Delta_{\mathrm{H}}$ & .24 & .003 & .28 & $<.001$ & .26 & $<.001$ \\
$\Delta_{\mathrm{BM}}$ & .32 & $<.001$ & .17 & .024 & .25 & $<.001$ \\
$\Delta_{\mathrm{Age}}$ & .43 & $<.001$ & .21 & .004 & .31 & $<.001$ \\
\hline
\end{tabular}

Note. $L=$ game location; $\Delta_{\mathrm{OR}}=$ difference in the end-of-previous season ordinal ranking; $\Delta_{\mathrm{PR}}=$ difference in the end-of-previous season points ranking; $\Delta_{\mathrm{GA}}=$ difference in the end-of-previous season goal-average per match ranking; $\Delta_{\mathrm{F}}=$ difference in the number of foreigners; $\Delta_{\mathrm{H}}=$ difference in the mean height of backcourt and pivot players; $\Delta_{\mathrm{BM}}=$ difference in the mean body mass of backcourt and pivot players; $\Delta_{\text {Age }}=$ difference in the mean age of backcourt and pivot players.

\section{Single regressions between physical differences between the teams and goal difference}

The anthropometric parameters $\left(\Delta_{\mathrm{H}}\right.$ and $\left.\Delta_{\mathrm{BM}}\right)$ of backcourt and pivot players were moderately and positively correlated with goal difference (r-values ranged from .24 to $.32,0.06<f^{2}<0.12$ ). Furthermore, the mean age difference of backcourt and pivot players $\left(\Delta_{\mathrm{Age}}\right)$ was positively correlated with goal difference. It was moderate in the $\mathrm{LNH}$ $\left(\mathrm{r}=.21 ; \mathrm{p}=.004, f^{2}=0.05\right)$ and large in the Bundesliga $\left(\mathrm{r}=.43, \mathrm{p}<.001, f^{2}=0.23\right)$. This correlation was synonymous with a link between the age of backcourt and pivot players and the goal difference, the older these players were, the better they impacted the final score difference. Last, the mean difference of foreigners per team appears to be very large and positively correlated in the Bundesliga $(\mathrm{r}=.70$, $\left.p<.001, f^{2}=0.96\right)$ but not in the LNH ( $\mathrm{r}=.12, \mathrm{p}>.05$, $f^{2}=0.01$ ), as previously mentioned. If we consider all games, the mean difference of foreigners per team appears to be moderately and positively correlated with the goal difference $\left(\mathrm{r}=.44, \mathrm{p}<.001, f^{2}=0.23\right)$.

\section{Single regressions between situational variables and goal difference}

The game location was positively correlated with goal difference in both the LNH and Bundesliga. However, this correlation was moderate in the Bundesliga $\left(\mathrm{r}=.35, \mathrm{p}<.001, f^{2}=0.14\right)$ and weak in the LNH $\left(\mathrm{r}=.21, \mathrm{p}=.006, f^{2}=0.06\right)$. Furthermore, the correlations observed between the quality of opposition indicators and the dependent variable, were quite similar in both leagues. Indeed, all of the values observed in both samples for the three quality of opposition indicators were correlated with goal difference with $\mathrm{r}$-values ranging between .60 and $.70\left(0.56<f^{2}<0.96\right)$. The best predictor for the Bundesliga, LNH and all games was the difference in the goal-average per match ranking at the end of the previous season $\left(\Delta_{\mathrm{GA}}\right.$, r-values ranged from .68 to .70 with $0.85<f^{2}<0.96-$ Figure 1$)$. 
Table 3. Multiple regression models for goal difference in three conditions (all $p<.001$ )

\begin{tabular}{lllllll}
\hline & Variables & Equations & $\mathrm{R}^{2}$ & $\mathrm{f}^{2}$ & $\mathrm{~F}$ & Error type \\
\hline \multirow{2}{*}{ Bundesliga } & $\mathrm{L}, \Delta_{\mathrm{GA}}, \Delta_{\mathrm{F}}, \Delta_{\mathrm{BM}}, \Delta_{\mathrm{Age}}$ & $4.14 \mathrm{~L}+0.011 \Delta_{\mathrm{GA}}+0.46 \Delta_{\mathrm{F}}+0.21$ & .67 & 2.03 & $\mathrm{~F}(5,146)=58.05$ & 3.80 \\
\multirow{2}{*}{$\mathrm{LNH}$} & $\mathrm{L}, \Delta_{\mathrm{BA}}+0.48 \Delta_{\mathrm{Age}}-2.07$ & .49 & 0.96 & $\mathrm{~F}(2,175)=87.31$ & 3.98 \\
\multirow{2}{*}{ All } & $\mathrm{L}, \Delta_{\mathrm{GA}}, \Delta_{\mathrm{F}}, \Delta_{\mathrm{Age}}$ & $\begin{array}{l}2.17 \mathrm{~L}+0.034 \Delta_{\mathrm{GA}}-1.09 \\
\Delta_{\mathrm{Age}}-1.51\end{array}$ & .56 & 1.27 & $\mathrm{~F}(4,325)=103.83$ & 4.00 \\
\hline
\end{tabular}

Note. L=game location; $\Delta_{\mathrm{GA}}=$ difference in the end-of-previous season goal-average per match ranking; $\Delta_{\mathrm{F}}=$ difference in the number of foreigners; $\Delta_{\mathrm{BM}}=$ difference in the mean body mass of backcourt and pivot players; $\Delta_{\mathrm{Age}}=$ difference in the mean age of backcourt and pivot players.

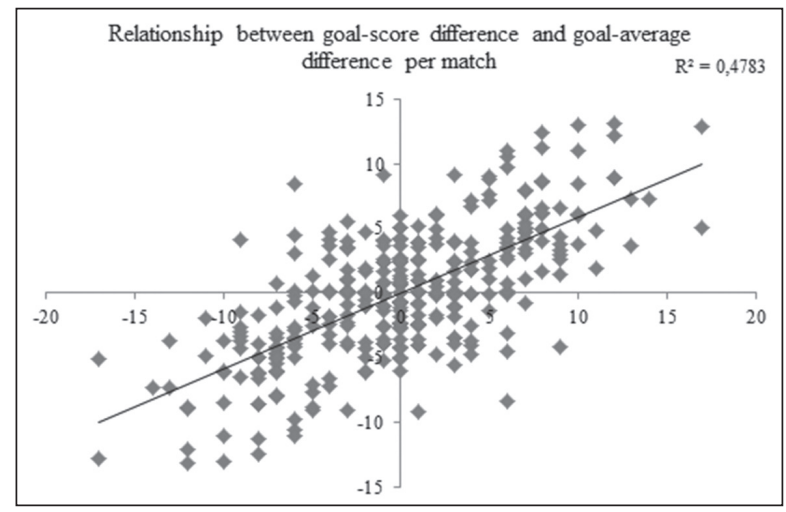

Figure 1. Relationship between goal difference and difference in the end-of-previous season goal-average per match ranking.

\section{Multiple regression model}

We tested all of the models including parameters that correlated strongly with goal difference. The best are summarized in Table 3 . The best model explained $56 \%$ of the total variance with standard error of four goals including four variables. The best model found for the Bundesliga explained $67 \%$ $\left(f^{2}=2.1\right)$ of the total variance with five variables, whereas the best model for the LNH explained $49 \%$ $\left(f^{2}=0.96\right)$ of the total variance with only two variables.

\section{Discussion}

\section{Single correlation study}

The first goal of this study was to investigate the influence of several variables on goal difference between opposing teams in the French and German national professional men's leagues. First, all of the variables studied are correlated with goal difference with different weights. Anthropometrical variables, such as body mass and height difference contribute less than $10 \%$ to the total variance (in both the LNH and Bundesliga). Several studies have shown that anthropometrical variables are linked with the ability to throw the ball at high velocity (Debanne \& Laffaye, 2011; Laffaye, et al., 2012). Furthermore, in comparing differences in anthropometric and physical fitness characteristics between elite and skilled players, Laffaye et al. (2012) showed that elite players were taller $(+7.75 \%)$ and heavier $(+24 \%)$ than skilled players, and had greater upper-limb strength $(+23 \%)$. Thus, Karcher et al. (2014) suggested that minimal body dimensions might be required, or at least be facilitators, to raise to the elite level in handball. However, all of those studies investigated these variables on heterogeneous samples, and this difference disappears when one focuses on an elite sample only. Indeed, mean body mass and height for back and pivot players are very similar and show a low variability $(97.9 \pm 3.3 \mathrm{~kg}$ and $1.94 \pm .02 \mathrm{~m}$ in the Bundesliga vs $95.9 \pm 2.1 \mathrm{~kg}$ and $1.93 \pm .02 \mathrm{~m}$ in the LNH). Such a poor variability explains low predictive power of the difference between two teams.

On the other hand, the location of the game contributes slightly to the final score difference, with $12 \%$ in the Bundesliga vs only $4 \%$ in the LNH. This difference could be explained in two ways. First, Agnew and Carron (1994) showed that crowd size positively influences the home court advantage, and the crowds are larger in Germany (about 4500 spectators per match) than in France (about 1500 spectators per match) ${ }^{1}$. Second, Pollard and Gomez (2009) highlighted a greater home court advantage in countries having greater regional autonomy and a distinct local cultural identity; Germany is organized as a federal system consisting of 16 federal states, while the State is centralized in France.

The difference in the number of foreign players on the team seems to be highly determinant in the final score difference in Germany, explaining almost half of the total variance, with a coefficient of determination amounting $49 \%$. On the other hand, these variables show an insignificant contribution of just $1 \%$ in France. In literature, the impact of foreigners on team performance seems to be linked to the actual number of foreigners on the team. Meletakos et al. (2016) examined the influence of foreign player recruitment by teams in Greek handball leagues from a quantitative viewpoint using the number of foreign players as a variable. They

\footnotetext{
${ }^{1}$ Source: findings of research on small groups Wikipedia.
} 
showed that initially, the arrival of foreign players had a negative effect on competitiveness due to their uneven distribution among top and bottom ranked teams. However, as their relative numbers increased, competitiveness improved, especially for the lower ranking teams. Enhancing team performance can be also explained from the findings of research on small groups. The general idea is that complex strategies require a broader pool of managerial knowledge and skills than relatively simple strategies. When facing complex and non-routine tasks, team performance is especially enhanced by compositional diversity (Jehn, Northcraft, \& Neale, 1999; Pelled, Eisenhardt, \& Yin, 1999). Moreover, focusing on the dynamics of teams with multicultural and multinational members, organizational researchers showed that a hybrid team culture may provide the basis for exchange and coordination within a diverse team, thus allowing the productive use of member talents and resources (e.g., Earley \& Mosakowski, 2000; Elron, 1997). These authors highlighted that cultural heterogeneity was positively related to team performance. More precisely, Earley and Mosakowski (2000) confirmed a curvilinear relationship between team heterogeneity on nationality and effective performance, with homogeneous and highly heterogeneous teams outperforming moderately heterogeneous ones in the long run. Further, the number of foreigners per team is quite similar in France and Germany (5.22 vs. 5.63) suggesting that this is not the main reason for this huge difference in influence. Nevertheless, the quality of foreigners in the two leagues is very different. The influx and quality of foreign players depends very much on a country's macroeconomic status (Meletakos, et al., 2016). Germany has the strongest economy in Europe, and there are many international players from top European teams (France, Denmark, Spain, Croatia, Poland, or Sweden) in the Bundesliga. On the other hand, in France, the foreigners are from Africa, South America, and with a few players from top European teams as shown by the players' lists of countries participating in the most recent World Championship in Qatar (2015)². More precisely, 234 international players play in other countries, with 69 of them playing in Germany, and just 37 in France, confirming the difference in the level of foreign players in these two leagues.

Three variables are also strongly linked to the final score difference, all of which are linked to the previous season's results: the ordinal ranking $\left(\mathrm{R}^{2}=.43\right.$ and $\mathrm{R}^{2}=.36$ in the Bundesliga and $\mathrm{LNH}$, respectively), the difference in the end-of-previous season points ranking $\left(\mathrm{R}^{2}=.46\right.$ and $\mathrm{R}^{2}=.39$ in the Bundesliga and LNH, respectively) and the differ- ence in the end-of-previous season goal-average per match ranking $\left(\mathrm{R}^{2}=.49\right.$ and $\mathrm{R}^{2}=.46$ in the Bundesliga and the LNH, respectively). Several studies have already revealed such a link with team quality, expressed as a final ranking or goal average ranking (e.g., Gomez, et al., 2014; Oliveira, Gomez, \& Sampaio, 2012). This direct link between the previous season's results and the current one could be explained by nearly constant team quality, low player turnover and relatively constant financial income for each team.

Last, age seems to influence team performance, but with a different weight in the two leagues. The all-games model reveals a shared variance of $10 \%$ but with great variability between the Bundesliga $\left(\mathrm{R}^{2}=.19\right)$ and the LNH $\left(\mathrm{R}^{2}=.04\right)$. It has been shown that age was directly and positively linked with professional experience (Ali \& Davies, 2003). However, there is no consensus in literature on the positive link between professional experience and performance; many studies have shown that experience is not linearly linked to performance (Schmidt, Hunter, \& Outbridge, 1986; Avolio, Waldman, \& McDaniel, 1990), while others considered this relationship to be positive (Campbell, 1990; Hunter, 1983; Schmidt, et al., 1986). Our study confirms this latter trend, without being able to provide a strong argument regarding the influence of this variable in the two countries since age was quite comparable in our sample (28.8 vs 27.5). Perhaps the link between age and experience is stronger in the Bundesliga than in France, with a younger starting age of the professional career in Germany. However, such data is not available.

\section{Multiple correlation study}

The second goal of this study was to predict goal differences in the two countries using multiple regression methods. Although a mixed linear model has been previously used to predict successful shots, counter-attacks shots and saves (Gomez, et al., 2014), to the best of our knowledge our study is the first to investigate goal differences or match results using this statistical approach. First, the models revealed that goal difference for two leagues was not explained by the same variables. The allgames model combining the German and French leagues explains $56 \%$ of the total variance by four variables: the location, the different end-of-previous season goal-average per match ranking, the mean age difference, and the difference in the number of foreigners. In this model, the best contributor is the difference in the end-of-previous season goalaverage per match ranking, which explains $86 \%$ of the variance; location explains $11 \%$ and the other two less than $2 \%$. This confirms the previous anal-

\footnotetext{
2 Source: International Handball Federation at http://www.ihf.info/enus/ihfcompetitions/worldchampionships/mensworld championships/menshandballworldchampionshipqatar2015/teaminfo.aspx
} 
ysis using the single regression analysis concluding that what happened in the previous season is a very strong predictor for the current one. This could be explained by the elite teams' relative financial stability from one season to the next. In both soccer (Lago-Peñas \& Sampaio, 2015) and handball (Lago-Peñas, Fernández-Villarino, Sánchez, Sampaio, 2016), Lago-Peñas and colleagues showed that higher-level clubs were ranked according to expectations based on their financial budgets at the end of the league. In the present study, the mean change of budget from 2014/2015 to 2015/2016 season in the LNH was $5.6 \%$, which is very low and the mean budget is 4.6 million euros. We see a similar profile of economic stability in Germany, with a mean budget of 4.15 million euros and a mean increase of $+2.2 \%$ from the previous to the current season (handnews.fr ${ }^{3}$ ). This stability allows a relative low player turnover between seasons, leading to the same team dynamics. When focusing on game location, the second contributor, our results confirm the previous one (Oliveira, et al., 2012; Lago Peñas, et al, 2013), i.e. that playing at home provides a slight advantage. Furthermore, Gomez and colleagues (2014) found the game location effect on successful counter-attack shots.

The model for the German league explains $67 \%$ of the variance by five variables. The difference in the goalaverage per match ranking at the end of the previous season explains $75 \%$ of the predicted final score, the location $14 \%$, the difference in the number of foreigners $6 \%$, and the difference in body mass and the age difference about $2 \%$. The model for the French league explains $49 \%$ of the variance, by just two variables. The difference in the goal-average per match ranking at the end of the previous season explains $93 \%$ of the final predicted score and the location $7 \%$. When looking at the equation, the coefficient of the location in both equations reveals that playing at home gives a two-goal advantage in the LNH and a four-goal advantage in the Bundesliga. Further, the impact of the difference in the goalaverage per match ranking at the end of the previous season is twice as high in the French league than in the Bundesliga, with a direct link in France and an advantage divided by two in Germany. The weight of the difference in the number of foreigners is one goal for every two foreigners, whereas the weight of the anthropometrical difference is negligible (one goal for every $5 \mathrm{~kg}$ of difference). So, the two models are close, except for the influence of foreigners in the Bundesliga. Foreign players in the Bundesliga are generally international players from elite handball countries (Denmark, Sweden and the Czech Republic), which greatly increases the teams' level, whereas foreigners in the LNH come from minor countries in Europe (Portugal and Italy) or from countries of other continents, such as Iran, Argentina and Tunisia.

Second, the model could be used to predict the match winner. For this purpose, we performed an analysis of residues which shows how the model predicts the score as a function of goal difference (Figures 2 and 3). The upper and right parts of the figures show true predictions of the winner (the score observed and predicted is positive) and the

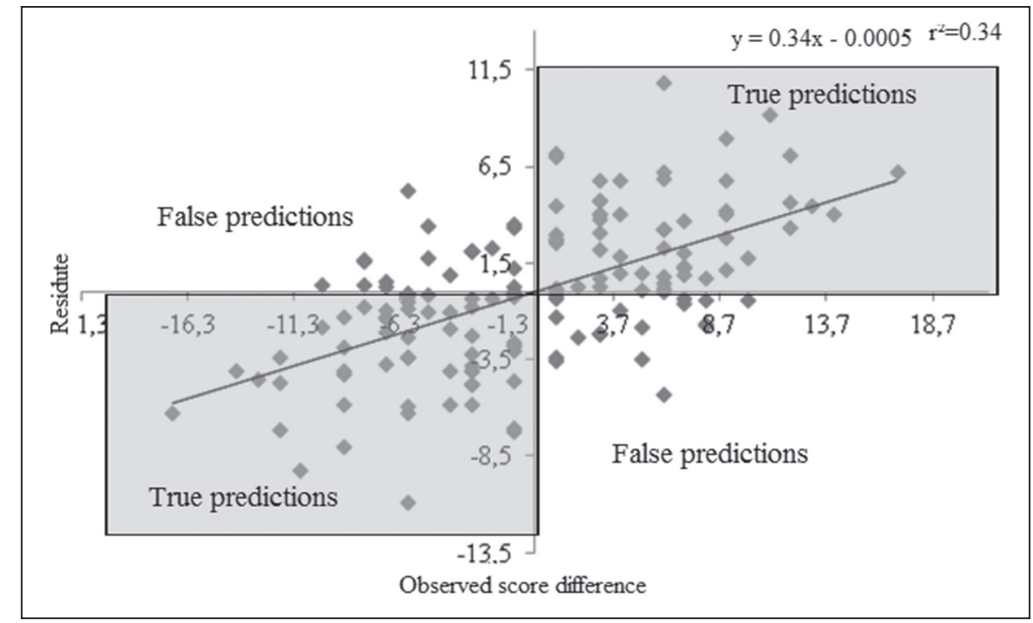

Figure 2. Analysis of residues for the Bundesliga.

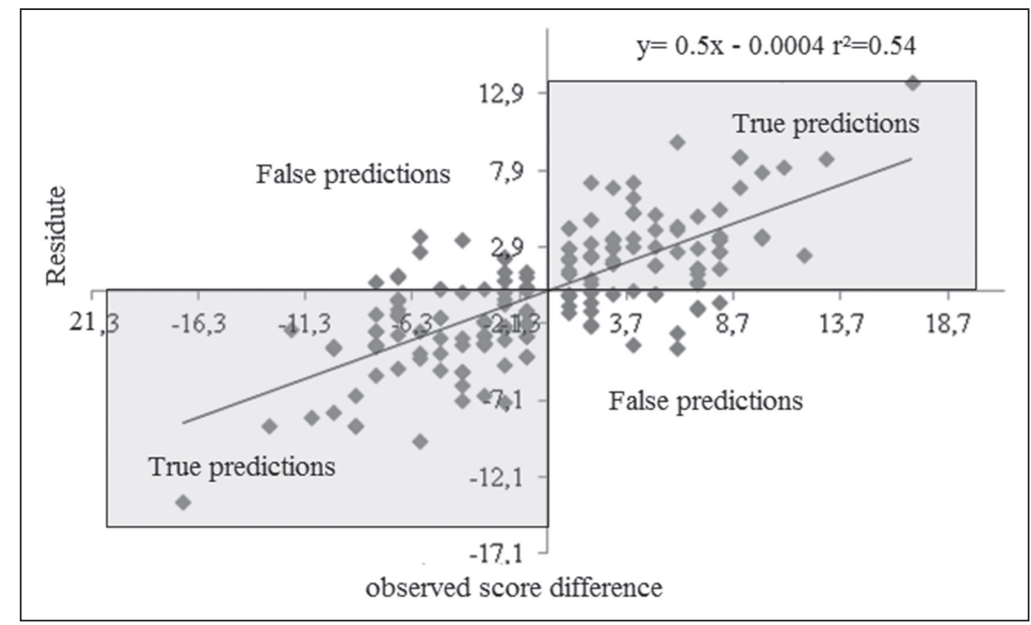

Figure 3. Analysis of residues for the LNH.

\footnotetext{
Source: http://handnews.fr/2015/lnh-les-budgets-de-la-saison-2015-2016/; http://handnews.fr/2015/all-les-budgets-des-18-clubspour-la-saison-20152016/
} 
lower and left part of the figure reveals true predictions of the loser (the score observed and predicted is negative). The other two parts of the figures reveal false predictions by the model. The model predicts the winner in $80 \%$ of the cases in the Bundesliga, and in $78 \%$ of the cases in the LNH, which could be considered as a good model. The error type of the multiple regression equations is about four goals, which is a moderate accuracy. When focusing on how the model predicts goal difference, the plots on the abscissa reveal a perfect fit between the observed and predicted values, whereas plots away from the abscissa reveal an inaccurate prediction. Moreover, the analysis of residues shows heteroscedasticity $\left(\mathrm{R}^{2}>10\right)$ as revealed by the linear regression between the observed score difference and the residue. In other terms, the model cannot accurately predict a large goal difference. The principal explanation for such a phenomenon is probably because when the score difference is great, the losing team does not really play all out to the end of the game so the difference increases dramatically. Indeed, for instance, in Figure 2, the point at the extreme right shows that a difference of 16 goals is overestimated from 13 goals.

\section{Applicability of the multiple-regression model}

To check the model's robustness, we tested the best combined model for both leagues on two independent samples (14 games from the Bundesliga and 16 games from the $\mathrm{LNH}$ ). We first calculated the multiple regression equation for new samples and then compared each variable within the equation with the initial theoretical model using a paired $t$-test. The equation for the independent sample for the LNH is

\section{Goal difference $=3.84 \mathrm{~L}+1.01 \Delta_{\mathrm{GA}}-1.92$}

with a comparable power of prediction $\left(\mathrm{R}^{2}=.49\right)$ and with a relative contribution of $82 \%$ for $\Delta_{\mathrm{GA}}$ and $18 \%$ for location. The $t$-test did not reveal any difference of coefficient for $\Delta_{\mathrm{GA}}$ but showed a high difference for location $(p<.0005)$, which reveals a weight in this equation twice that of the first. This could be due to the period chosen for the sample, which was the first three games of the season, which are not necessarily the most representative games of an entire season.

The equation for the independent sample for the Bundesliga is

Goal difference $=3.7 \mathrm{~L}+0.7 \Delta_{\mathrm{GA}}-0.34 \Delta_{\mathrm{F}}+0.21$ $\Delta_{\mathrm{BM}}+0.7 \Delta_{\mathrm{Age}}-1.85$

which is very close to the original model, with quite similar coefficients and a comparable power of prediction $\left(\mathrm{r}^{2}=.76\right)$. The $t$-test did not reveal any difference of coefficient for $\Delta_{\mathrm{GA}}, \Delta_{\mathrm{F}}, \Delta_{\mathrm{Age}}$ nor $\Delta_{\mathrm{BM}}$, but showed a difference for location $(\mathrm{p}<.01)$ despite a comparable weight on the game (about + four goals for the home team). Consequently, the model seems robust, with the same multiple variables and predictive power, although it does reveal some differences due to the impact of atypical earlyseason games on the model with a small sample.

\section{Limitations}

The present study has two limitations. First, anthropometrical variables were collected from each league's official website. Consequently, the reliability of these data has not been checked. This seems particularly salient for body mass which is sensitive to small fluctuations over the course of an entire season. Second, the models are based on the initial team composition and do not take player turnover into account.

\section{Conclusion}

The model found shows that it is possible to use relevant variables to predict a handball game's winner and loser and its goal difference. The model predicts the winner in $79 \%$ of cases with a mean accuracy of four goals. Multi-regression models reveal a high contribution of the difference of the end-of-previous season goal-average per match ranking and the location to goal difference, while they highlight difference in the way games are won in the leagues with a contribution of foreigners, anthropometric characteristics and age in the Bundesliga. Coaches and team sport managers could consider these findings when recruiting and selecting players.

\section{References}

Agnew, G.A., \& Carron, A.V. (1994). Crowd effects and the home advantage. Journal of Sport Psychology, 25, 53-62.

Ali, H., \& Davies, D.R. (2003). The effects of age, sex and tenure on the job performance of rubber tappers. Journal of Occupational and Organizational Psychology, 76, 381-391.

Avolio, B.J., Waldman, D.A., \& McDaniel, M.A. (1990). Age and work performance in nonmanagerial jobs: The effects of experience and occupational type. Academy of Management Journal, 33, 407-422.

Campbell, J. (1990). Modeling the performance prediction problem in industrial and organizational psychology. In M. Dunnette \& L. Hough (Eds.), Handbook of industrial and organizational psychology. Palo Alto, CA: Consulting Psychologists Press. 
Cohen, J. (1988). Statistical power analysis for the behavior sciences. Hillsdale, NJ: Lawrence.

Debanne, T., \& Laffaye, G. (2011). Predicting the throwing velocity of the ball with anthropometric factors and isotonic tests in handball. Journal of Sports Science, 29, 705-713.

Earley, P.C., \& Mosakowski, E. (2000). Creating hybrid team cultures: An empirical test of transnational team functioning. The Academy of Management Journal, 43 (1), 26-49.

Elron, E. (1997). Top management teams within multinational corporations: Effects of cultural heterogeneity. Leadership Quarterly, 8, 393-412.

Gómez, M.A., Lago-Peñas, C., Viaño, J., \& González-Garcia, I. (2014). Effects of game location, team quality and final outcome on game-related statistics in professional handball close games. Kinesiology, 46(2), 249-257.

Gréhaigne, J-F., \& Godbout, P. (1995). Tactical knowledge in team sports from a constructivist and cognitivist perspective. Quest, 47, 490-505.

Hopkins, W.G., Marshall, S.W., Batterham, A.M., \& Hanin, J. (2009). Progressive statistics for studies in sports medicine and exercise science. Medicine and Science in Sports and Exercise, 41(1), 3-13.

Howell, D.C. (2010). Statistical methods for psychology ( $7^{\text {th }}$ ed.). Belmont, CA: Wadsworth.

Hunter, J.E. (1983). A causal analysis of cognitive ability, job knowledge, job performance and supervisory ratings. In F. Landy, S. Zedeck \& J. Cleveland (Eds.), Performance measurement and theory (pp. 257-266). Hillsdale, NJ: Lawrence Erlbaum Associates.

Jehn, K.A., Northcraft, G.B., \& Neale, N.A., (1999). Why differences make a difference: A field study of diversity, conflict, and performance in workgroups. Administrative Science Quarterly, 44(4), 741-763.

Karcher, C., Ahmaidi, S., \& Buchheit, M. (2014). Body dimensions of elite handball players with respect to laterality, playing positions and playing standard. Journal of Athletic Enhancement, 3(4), doi:10.4172/2324-9080.1000160

Karcher, C., \& Buchheit, M. (2014). On-court demands of elite handball, with special reference to playing positions. Sports Medicine, 44(6), 797-814.

Laffaye, G., Debanne, T., \& Choukou M.A. (2012). Is the ball velocity dependent on expertise? A multi-dimensional study in handball. International Journal of Performance Analysis in Sport, 12, 629-642.

Lago-Peñas, C., Fernández-Villarino, M., Sánchez, P., Sampaio, J. (2016). The impact of a good season start on team performance in elite handball. Journal of Human Kinetics, 50, 192-202.

Lago-Peñas, C., Gómez, M. A., Viaño, J., \& González-García, I. (2013). Home advantage in elite handball: The impact of the quality of opposition on team performance. International Journal of Performance Analysis in Sport, 13(3), 724-733.

Lago-Peñas, C., \& Sampaio, J. (2015). Just how important is a good season start? Overall team performance and financial budget of elite soccer clubs. Journal of Sports Sciences, 33(12), 1214-1218.

Meletakos, P., Chatzicharistos, D., Apostolidis, N., Manasis, V., \& Bayios, I. (2016). Foreign players and competitive balance in Greek basketball and handball championships. Sport Management Review, 19(4), 391-401.

O’Donoghue, P. (2015). An introduction to performance analysis of sport. New York: Routledge.

Oliveira, T., Gómez, M., \& Sampaio, J. (2012). Effects of game location, period, and quality of opposition in elite handball performances. Perceptual and Motor Skills, 114, 783-794.

Pelled, L.H., Eisenhardt, K.M., \& Xin, K.R. (1999). Exploring the black box: An analysis of work group diversity, conflict, and performance. Administrative Science Quarterly, 44, 1-28.

Pollard, R., \& Gómez, M.A. (2012). Re-assessment of home advantage in Spanish handball: Comment on Gutierrez, et al. (2012). Perceptual and Motor Skills, 115(3), 937-943.

Schmidt, F.L., Hunter, J.E., \& Outerbridge, A.N. (1986). Impact of job experience and ability on job knowledge work sample performance, and supervisory rating of job performance. Journal of Applied Psychology, 71(3), 432-439.

Submitted: April 5, 2016

Accepted: October 12, 2016

Correspondence to:

Thierry Debanne

Université Paris-Est, LIRTES (EA 7313), UPEC,

UPEMLV,

F-94010, Créteil, France

E-mail: thierry.debanne@u-pec.fr 